\title{
Os catalisadores e suas formas de resistência e luta na teoria crítica de Herbert Marcuse
}

\author{
The catalysts and their forms of resistance and fighting in the critical theory \\ of Herbert Marcuse
}

\author{
RENÊ IVO DA SILVA LIMA ${ }^{1}$
}

\begin{abstract}
Resumo: O objetivo deste artigo é apresentar as formas de resistência e luta dos catalisadores na teoria crítica de Herbert Marcuse. O problema que esta pesquisa levanta é o seguinte: quais são as tendências da sociedade unidimensional que podem reativar o pensamento e comportamento revolucionário da classe trabalhadora? A conclusão a qual chegamos é que as tendências que podem reativar o pensamento e práxis revolucionária da classe trabalhadora são os catalisadores. Estes, através das suas formas de resistência e luta, tentam mostrar a irracionalidade do modo de vida existente, tentam fazer ressurgir a consciência e ação radical capaz de destruir a sociedade unidimensional.
\end{abstract}

Palavras-chave: Integração. Catalisador. Tipos de catalisador. Formas de resistência e luta.

Abstract: The objective of this article is to present the forms of resistance and struggle of the catalysts in the critical theory of Herbert Marcuse. The problem that this research raises is the following: what are the tendencies of the one-dimensional society that can reactivate the revolutionary thought and behavior of the working class? The conclusion we come to is that the tendencies that can reactivate revolutionary thought and praxis of the working class are the catalysts. These, through their forms of resistance and struggle, try to show the irrationality of the existing way of life, try to resurrect the consciousness and radical action capable of destroying the one-dimensional society.

Keywords: Integration. Catalyst. Types of catalysts. Forms of resistance and struggle.

\section{Introdução}

“... a tarefa de um intelectual, é em primeiro lugar uma missão de educação radical."

(Herbert Marcuse)

Para Marx e Engels, a filosofia não podia mais limitar-se a explicar a realidade, ela já demonstrara de maneira satisfatória sua capacidade de cumprir essa tarefa. Acreditando que essa ciência poderia ultrapassar a mera interpretação das relações sociais existentes, os filósofos alemães atribuíram mais uma função à filosofia: a de transformar o mundo ${ }^{2}$. Nesse sentido, "A realização da filosofia implica a transformação da ordem social e, por conseguinte, a crítica desta” (OLIVEIRA, 2012,

1 Graduando em Filosofia pela Universidade Estadual do Ceará - UECE. Bolsista de Iniciação Científica - IC/UECE. Membro do Grupo de Estudos e Pesquisas "Atualidade do pensamento de Herbert Marcuse".

Lattes: http://lattes.cnpq.br/5208415662639119 Facebook: https://www.facebook.com/rene.ivo.

Email: reneivo@hotmail.com

${ }^{2}$ Nas Teses sobre Feuerbach, Marx afirma que "Os filósofos apenas interpretaram o mundo de diferentes maneiras; o que importa é transformá-lo” (MARX, 2007, p. 539). 
p. 32). A nova tarefa atribuída à ciência filosófica não deixou de ter seus críticos, mas também não deixou de ter seus adeptos.

Um desses simpatizantes foi justamente Herbert Marcuse, este dera continuidade ao projeto marxista de compreender, explicar e transformar a ordem dos fatos; ele fora capaz de entender os problemas de seu tempo, e teve a "coragem" de denunciar as interpretações equivocadas que alguns stalinistas fizeram sobre a teoria social de Marx e Engels. Marcuse prosseguiu desenvolvendo uma teoria crítica que fosse capaz de apresentar as contradições da civilização estabelecida, que fosse capaz de projetar um futuro melhor, em outras palavras, uma teoria crítica comprometida com a emancipação dos seres humanos.

De acordo com Marx, o proletariado era a contradição, a negação viva da sociedade capitalista porque não participava dos benefícios dessa sociedade, não tinha nenhuma riqueza acumulada, o salário dos trabalhadores mal dava para sustentar as necessidades básicas de alimentação, vestuário e moradia de sua família. Para ele, somente os sem propriedade, os miseráveis, isto é, o proletariado poderia ser o agente histórico da revolução socialista:

O conceito marxista estipulou que somente aqueles que estavam livres dos benefícios do capitalismo seriam possivelmente capazes de transformá-lo numa sociedade livre; aqueles cuja existência era a própria negação da propriedade capitalista poderiam tornar-se os agentes históricos da libertação (MARCUSE, 2015, p. 14-15).

Na primeira metade do século XX, Marcuse percebera que a comodidade fornecida pelo aprimoramento da tecnologia estava conseguindo reduzir a oposição radical da classe trabalhadora à sociedade unidimensional ${ }^{3}$. Nas sociedades industriais avançadas, a maioria dos trabalhadores participa dos confortos oferecidos pelo sistema capitalista e acabam se conformando com a ordem social estabelecida. $\mathrm{O}$ resultado disso é a redução da necessidade de uma revolução socialista. Assim, um dos principais problemas levantado pela teoria crítica de Herbert Marcuse, é o de descobrir as tendências que podem contribuir com reativação da consciência e práxis revolucionária da classe trabalhadora.

O objetivo geral deste artigo é apresentar as formas de resistência e luta dos catalisadores na teoria crítica de Herbert Marcuse. O problema que esta pesquisa levanta é o seguinte: quais são as tendências da sociedade unidimensional que podem reativar o pensamento e comportamento revolucionário da classe trabalhadora? Para fundamentar o objetivo geral, este artigo tem como objetivos específicos: 1) compreender o processo de integração da classe trabalhadora à sociedade

\footnotetext{
3 Por "sociedade unidimensional" compreendemos a ordem social estabelecida, cujo principal objetivo é tentar dominar toda oposição às relações sociais existentes; tentar controlar toda contestação ao estado de coisas vigente. Portanto, sociedade unidimensional é a sociedade que tenta conter todas as possibilidades e alternativas de uma vida qualitativamente melhor.
} 
unidimensional; 2) expor o significado do conceito catalisador e 3) apresentar os tipos de catalisador e suas formas de resistência e luta.

A justificativa que nos levou a desenvolver este artigo foi a situação presente da sociedade capitalista contemporânea. A crise atual do sistema capitalista trouxe mais desemprego, perda de direitos trabalhistas, redução de gastos públicos (saúde, educação, etc.), tal situação oprime os trabalhadores e torna sua vida ainda mais difícil e ruim. Assim, o motivo que nos impulsionou a produzir esse artigo foi incentivar uma discussão sobre as alternativas que podem dar início a superação das contradições da sociedade unidimensional. Ao expor o pensamento de Marcuse sobre as tendências que poderiam iniciar a destruição da sociedade capitalista nas décadas de 60 e 70, essa pesquisa tenta estimular a discussão sobre as alternativas que podem iniciar a destruição da sociedade capitalista hoje.

$\mathrm{Na}$ primeira seção, compreendemos o processo de integração da classe trabalhadora à sociedade unidimensional. Esta civilização, por meio dos confortos oferecidos pela tecnologia, está conseguindo integrar a classe trabalhadora ao modo de vida vigente. Na segunda seção expomos, de modo geral, o sentido do conceito "catalisador". Este significa as tendências quantitativamente menores de desintegração existentes no status quo, que podem romper a consciência administrada da classe trabalhadora e reativar seu pensamento e práxis revolucionária. Na terceira seção apresentamos os tipos de catalisador e suas formas de resistência e luta, a saber: 1) os movimentos de libertação nacional nos países subdesenvolvidos; 2) as novas estratégias dos trabalhadores na Europa; 3) os estratos desprivilegiados da sociedade unidimensional; 4) a intelligentsia opositora e 5) os movimentos de contestação nos países soviéticos ${ }^{4}$. Suas formas de resistência e luta são as seguintes: o primeiro catalisador apresenta a estratégia da luta armada; o segundo desenvolve o método de reconstrução dos "sovietes"; o terceiro a resistência à uma vida miserável e o quarto elabora a estratégia de recusa do modelo de vida imposto e das manifestações de rua.

A conclusão a qual chegamos é que os catalisadores, através de suas formas de resistência e luta, tentam mostrar a irracionalidade do modo de vida existente, tentam fazer ressurgir a consciência e ação radical capaz de destruir a sociedade unidimensional.

\section{A integração da classe trabalhadora à sociedade unidimensional}

O novo estágio da sociedade capitalista - a sociedade unidimensional desenvolveu novas formas de controlar a classe trabalhadora, esses novos modos de dominação estão conseguindo impor uma administração quase total da consciência e comportamento da classe dominada. Se antes do desenvolvimento da sociedade

${ }^{4}$ Nosso artigo limitar-se-á a apresentar as formas de resistência e luta do primeiro, segundo, terceiro e quarto tipo de catalisador. 
unidimensional o controle das forças de oposição se dava principalmente por meio da repressão violenta da polícia, do exército, etc., agora, com o surgimento daquele novo estágio, a dominação se dá através dos confortos proporcionados pelo aperfeiçoamento tecnológico.

Na civilização estabelecida, a tecnologia está organizada para satisfazer os interesses particulares da classe dominante, está direcionada para garantir lucro à classe burguesa, assim, "Sob esse aspecto a tecnologia e o conforto tornaram-se impedimentos de libertação: (...) tornaram-se forças de contenção" (SILVA, 2015, p. 149-50). Nessa civilização, o aparato tecnológico produz e distribui, de maneira cada vez mais ampla, artigos de luxo que tornam agradável a vida na sociedade existente. O conforto proporcionado pelos aparelhos $W i-F i$, pelos automóveis e pelo entretenimento no tempo de lazer impedem que a classe trabalhadora lute por uma existência verdadeiramente livre, isto é, por uma sociedade sem miséria, sem labuta (trabalho exaustivo) e com tempo livre ${ }^{5}$ para a satisfação das necessidades e desenvolvimento de todas as faculdades humanas.

O principal resultado desse novo modo de dominação é a aceitação da ordem prevalecente e a conformação com estado de coisas vigente. Aqui, a capacidade de contestação da classe oprimida é reduzida, seu pensamento crítico e negativo, que é capaz de perceber, apreender e resolver as contradições, é absolvido pelas formas de administração. Com a redução contínua desse pensamento, "A classe explorada não consegue mais reconhecer suas próprias necessidades (...)” (IVO, 2016, p. 3), é impedida de perceber, recusar e transformar o modo de organização social presente.

Há uma identificação com o modelo de pensamento e comportamento presentes e uma falsa reconciliação dos interesses contrários das classes antagônicas, em outras palavras, acontece o que Marcuse denomina de integração da classe trabalhadora. Essa integração "altera o caráter de oposição das classes trabalhadoras que deixam de constituir a negação do capitalismo e são assimiladas 'confortavelmente' à ordem estabelecida” (PISANI, 2012, p. 605). A crescente unificação dos opostos une as necessidades e aspirações dos opressores e oprimidos, os dominados tornam seus, os interesses dos dominantes e, dessa maneira, organizam e direcionam suas vidas exclusivamente para a conquista de objetivos que lhe são alheios. Assim, quanto mais assimilados forem os explorados, quanto mais integrados estiverem os trabalhadores, mais facilmente a sociedade estabelecida perpetua-se.

\footnotetext{
${ }^{5}$ No seu livro $O$ homem unidimensional, Marcuse chama atenção para a diferença no sentido dos termos "tempo livre" e "tempo de lazer". Segundo ele, "o último floresce na sociedade industrial avançada, mas é não-livre no sentido em que é administrado pelos negócios e pela política" (MARCUSE, 2015, p. 78).
} 


\section{O significado do conceito "catalisador"}

Mesmo com o crescente processo de integração da classe trabalhadora, Marcuse não cai no pessimismo, ele compreende que na civilização prevalecente existem tendências capazes de desintegrar a consciência e o comportamento administrado das forças de oposição. Como todo autêntico revolucionário, o filósofo não se rende às formas de controle, sua teoria é um modo de resistência e luta, seu pensamento está sempre voltado para a elaboração de alternativas que possam contribuir com o desenvolvimento da libertação e emancipação humanas. Ele jamais perdeu as esperanças na humanidade e no seu poder de transformar a realidade quando se apropria das ideias revolucionárias, pois, "a teoria também se torna força material quando se apodera das massas" (MARX, 2013, p. 157).

Para Marcuse, "Em virtude da sua posição básica no processo de produção, em virtude de sua importância numérica e do peso da exploração, a classe trabalhadora é ainda o agente histórico da revolução (...)" (MARCUSE, 1977, p. 30), entretanto, estão integrados demais para compreender. Para fazer frente a essa integração, o filosofo apresenta algumas tendências de desintegração, a saber, os catalisadores.

$\mathrm{Na}$ teoria crítica de Herbert Marcuse, o conceito "catalisador" significa as tendências de desintegração existentes na sociedade unidimensional, que podem romper a consciência administrada da classe trabalhadora. São forças quantitativamente menores de oposição à civilização estabelecida, que podem incentivar o ressurgimento do pensamento e comportamento radical, crítico e negativo das forças quantitativamente maiores (classe trabalhadora) de oposição ao status quo. São grupos de contestação da realidade vigente que podem estimular a reativação da consciência e práxis revolucionária dos trabalhadores.

A tarefa dos catalisadores consiste em restituir mais uma vez o Eros revolucionário entre a classe trabalhadora, isto é, o desejo de união para a construção de uma sociedade qualitativamente diferente e melhor. Seu objetivo é fazer com que os trabalhadores se reconheçam novamente como sujeito revolucionário e identifiquem quem são seus verdadeiros inimigos e quais são seus reais interesses. Seu dever é descobrir as contradições da sociedade predominante e mostrar àquela classe as formas de dominação que os impedem de destruir a sociedade capitalista. 


\section{Os tipos de catalisador 6}

\subsection{Os movimentos de libertação nacional nos países subdesenvolvidos}

A luta dos "condenados da terra" nos países subdesenvolvidos é, ao mesmo tempo, a recusa da política de exploração dos seus governos nacionais - marionetes servis da política neoimperialista desenvolvida pelas sociedades industriais avançadas - e uma tentativa - mesmo que seus combatentes não saibam - de se livrar da dominação das relações sociais unidimensionais vigentes nessas civilizações. Essa luta expressa uma ameaça para àquelas sociedades porque pode servir para denunciar suas atrocidades repressivas e mostrar que é possível recusar e combater o modo de vida imposto pelo sistema vigente.

As sociedades industriais avançadas, principalmente os "Estados Unidos, que ainda é o protetor do 'capital como um todo"' (MARCUSE, 1973, p. 31), precisa conter as forças rebeldes para assegurar a continuidade do estado de coisas estabelecido e prevenir qualquer movimento que possa iniciar a ruptura da sólida estrutura do sistema de classes. Com esse objetivo, os extratos interessados na manutenção do establishment investem muito bem na preparação das suas forças de defesa. Essa preparação consiste em equipamento material, estudo das estratégias de interrogatórios e treinamento espiritual das forças armadas, guarda nacional, polícia etc.

Os equipamentos não se limitam a balas de borracha, cassetetes e coletes a prova de bala, também são produzidos para deformar em massa (armamento químico), para incendiar vilarejos (napalm no Vietnã) e destruir cidades inteiras (bombas atômicas). A tortura foi uma das principais estratégias utilizadas para interrogar os integrantes dos movimentos de libertação. No que se refere ao treinamento mental das forças de proteção do status quo, "seus espíritos e corpos já estão treinados para ver, ouvir e cheirar no outro não um ser humano mas um animal - animal, contudo, sujeito a castigo total” (MARCUSE, 1977, p.102).

Quando se trata de prevenção, não há limites para a brutalidade, para proteger o status quo vale tudo: torturar, assassinar, incendiar "cessam de ser crimes, se servem para preservar e ampliar o 'Mundo Livre”' (MARCUSE, 1977, p. 102). É dessa maneira que a sociedade de consumo está conseguindo impedir as tendências que poderiam minar o modo de organização social existente, sua capacidade de integrar e destruir

\footnotetext{
${ }^{6}$ De acordo com Silvio Ricardo Gomes Carneiro, na sua resenha dos Collected papers of Herbert Marcuse, (marxism, revolution and utopia): "É possível detectar ao menos cinco catalisadores que atingem cada vez mais o coração do sistema: os movimentos de libertação nacional, as 'novas estratégias' dos trabalhadores europeus (em grande medida contrária à administração de suas lutas), os movimentos daqueles 'desprivilegiados' nas sociedades afluentes, a intelligentsia opositora e, por fim, os movimentos de contestação nos países soviéticos (como na ex-Tchecoeslováquia)" (CARNEIRO, 2015, p. 222). Nosso artigo limitar-se-á a apresentar e explicar as formas de resistência e luta do primeiro, segundo, terceiro e quarto tipo de catalisador citado por Silvio Ricardo Gomes Carneiro.
} 
as forças de ruptura são seus principais mecanismos de defesa. Porém, os movimentos de libertação nos países subdesenvolvidos resistem e lutam contra a exploração de seus corpos e de sua terra. Entre as cinco tendências catalisadoras apresentadas anteriormente ${ }^{7}$, Marcuse afirma que

(...) o catalisador principal (...) parece ser a primeira: o movimento de libertação nacional. Combatendo contra as guerras de libertação, a sociedade do bem-estar combate pelo seu futuro, pelo seu potencial de matérias-primas, pelo trabalho a baixo custo e pelos investimentos (MARCUSE, 1972, p. 202).

O potencial revolucionário de tais movimentos não se restringe ao protesto desordeiro, a passeata com cartazes, a negação do comportamento padrão, vai além, é uma questão de vida ou morte, aqui, o problema se coloca de maneira mais decisiva, a palavra de ordem é: viver uma vida livre ou não viver. Nos confrontos pela libertação na África e na Ásia, a recusa dos oprimidos se manifesta em luta armada, violência necessária para acabar com as forças que produzem e utilizam a violência para continuar em suas posições privilegiadas. O objetivo da violência do oprimido é diferente da violência do opressor, a primeira aspira libertar a maioria dos indivíduos, a segunda, dominar a maioria dos indivíduos ${ }^{8}$.

Talvez seja por conta da maneira que se desenvolve os conflitos nos países subdesenvolvidos (luta armada) que a civilização existente esteja impondo um excesso de agressividade aos movimentos de libertação, o medo de que essa tendência sirva de exemplo teórico e prático para o resto dos dominados exige repressão total por parte do sistema dominante. "Um triunfo do movimento de libertação nacional pode ser também o sinal para o início de movimentos similares em outras zonas do mundo (...)" (MARCUSE, 1972, p. 202-3) O fator decisivo desse processo não é tanto a "audácia" do confronto armado, mas o surgimento de novos rebeldes preparados para o combate.

O surgimento da consciência de que "o sistema em seu conjunto se revela ser este 'crime contra a humanidade' (...)” (MARCUSE, 1993, p. 12, tradução nossa) é essencial para mostrar que essa sociedade é capaz de aniquilar os grupos de indivíduos que contestem e queiram desacreditar o modo de organização social vigente. Aquela consciência é fundamental para que os explorados percebam e compreendam que uma civilização capaz de destruir ambientes inteiros com o objetivo de obter lucro não pode continuar existindo. Para ela - a civilização existente - o que está em jogo não é a perpetuação de uma vida melhor para todas as pessoas. $\mathrm{O}$

\footnotetext{
7 Ver nota 5 .

${ }^{8}$ John Karley de Sousa Aquino, no seu artigo O conceito de cálculo histórico em Herbert Marcuse, faz a distinção entre "violência revolucionária" e "violência reacionária". Segundo Aquino, "No contexto dramático de guerras civis decorrente de processos revolucionários, tanto os reacionários quanto os revolucionários usarão da violência, os primeiros para manter inalterado o status quo e os segundos para transformá-lo" (AQUINO, 2016, p. 7).
} 
que realmente importa é prolongar uma vida melhor para um punhado de ricos à custa do trabalho exaustivo da maioria dos indivíduos.

Portanto, de acordo com Marcuse, os movimentos de libertação no Terceiro Mundo são "a negação determinada do sistema, enfrentando-o e combatendo-o enquanto totalidade" (MARCUSE, 1993, p. 12, tradução nossa). São a resistência mais forte que o sistema tem de enfrentar porque não lutam apenas por melhores condições de vida dentro da comunidade predominante, lutam pela destruição de toda a realidade existente e pela construção de uma nova ordem social capaz de acabar com a miséria e a mais-repressão ${ }^{9}$ imposta pelas classes opressoras. $\mathrm{O}$ corpo desses homens e mulheres não aguenta mais ser mutilado e deformado pela guerra, pela agressão, pela brutalidade do establishment.

\subsection{As novas estratégias dos trabalhadores na Europa}

Para Marcuse, o movimento dos trabalhadores na França e na Itália ainda é forte, apesar de os partidos comunistas nesses países não estarem totalmente comprometidos com a revolução e "aderirem a um programa mínimo que deixa de lado a tomada revolucionária do poder e age de acordo com as regras do jogo parlamentar" (MARCUSE, 2015, p. 56). A consciência desses trabalhadores não foi totalmente absorvida pelos confortos da civilização existente, resta-lhes a razão crítica necessária para contestar a realidade imposta. As expressões de descontentamento dos trabalhadores nos países centrais do capitalismo de monopólio podem iniciar a ativação do processo de desintegração da classe oprimida.

Visto que a sociedade unidimensional desenvolveu novas formas de dominar o agente revolucionário, nem todos os meios de luta utilizados pelos trabalhadores na segunda metade do século XIX e início do século XX tem êxito no confronto de classes da civilização prevalecente. Na Revolução Russa, algumas características tradicionais da luta de classes elaboradas pela teoria social do século passado, ainda puderam ser construídas e contribuíram de maneira decisiva para o embate entre os classes antagônicos. Tais características foram "a liderança de uma 'vanguarda ideologicamente consciente', o partido de massa como seu 'instrumento', o objetivo básico a 'luta pelo poder estatal”' (MARCUSE, 1973, p. 17).

No sistema de capitalismo-monopolista algumas dessas características podem estar com sua validade comprometida, por exemplo, a característica do partido de massa como instrumento revolucionário. Parece inexistir um partido de massa verdadeiramente comprometido com a revolução socialista, acontece justamente o contrário, os políticos profissionais estão satisfeitos com seus cargos bem

\footnotetext{
9 Segundo Marcuse, em Eros e civilização, o conceito "mais-repressão" significa os "(...) controles adicionais acima e além dos indispensáveis à associação civilizada humana. Esses controles adicionais, gerados pelas instituições específicas de dominação, receberam de nós o nome de mais-repressão" (MARCUSE, 2015, p. 29).
} 
remunerados. Limitam-se a conquistar o parlamento, se comprometem a executar um programa mínimo de bem-estar para os trabalhadores dentro do estado de coisas predominante. Atrasam a mudança radical com as políticas de reconciliação dos interesses antagônicos das classes.

O enfraquecimento do controle da classe opressora sobre a classe oprimida requer a criação de novas estratégias de combate capazes de desintegrar a consciência integrada e romper a sólida estrutura do sistema. "Na França e na Itália, a radicalização das exigências econômicas do sindicalismo e de toda a estratégia esquerdista (...)” (MARCUSE, 1973, p. 42) são exemplos das novas táticas que estão surgindo no conflito contra o poder da sociedade unidimensional. A união entre os trabalhadores não administrados e a Nova Esquerda ${ }^{10}$ radical é essencial para o processo de emancipação da classe explorada.

A ação conjunta dessas duas forças de oposição (trabalhadores e Nova Esquerda) é necessária porque as estratégias propostas pelo setor intelectual da Nova Esquerda só podem vir a ter êxito se for aderida e construída em conjunto pelas duas forças de contestação. As táticas têm de ser capazes de resistir à reação das forças contra-revolucionárias, precisam ser compreendidas, corresponder às aspirações dos trabalhadores e adaptar-se, de modo eficaz, às novas formas de luta. Em Marcuse, a reconstrução dos "sovietes" (Räte) ou "conselhos" é um método poderoso para a efetivação da libertação.

Para o filósofo alemão, "Os conselhos serão órgãos da revolução tão-só à medida que representem o povo em revolta" (MARCUSE, 1973, p. 51). Os sovietes seriam o instituto de pesquisa e estudo da teoria e ação transformadora, enquanto instituição revolucionária poderia ser o centro de educação socialista dos trabalhadores, eles seriam o núcleo de preparação dos proletários para a luta de classes, sua função consistiria em fazer surgir mais uma vez a união, a solidariedade e a cooperação entre a classe dominada. Nas organizações para a revolução, os homens e mulheres dominados seriam educados para pensar e agir de forma autônoma.

Os conselhos são associações políticas e radicais qualitativamente distintas das instituições sociais da comunidade predominante, o modo de organização desses órgãos difere segundo a finalidade que almejam alcançar. As primeiras servem à libertação da classe trabalhadora, as segundas auxiliam na repressão dessa classe.

Segundo Isabel Loureiro, "Falar em conselhos significa falar em democracia direta, ou democracia radical (em oposição à democracia representativa)" (LOUREIRO, 2006, p. 99). A reconstrução dos sovietes não se limita às fábricas ou indústrias, mas estende-se aos bairros, às escolas etc., os membros escolhidos para representar os trabalhadores são retirados dos próprios grupos de proletários. As

\footnotetext{
${ }^{10}$ Movimento intelectual de oposição radical às sociedades industriais avançadas surgido na segunda metade do século XX.
} 
pessoas eleitas são controladas pelos homens e mulheres que os elegeram, caso os representantes não estejam verdadeiramente engajados com a causa revolucionária podem perder seu "mandato" a qualquer momento.

Dessa maneira, "o controle dos representantes pelos representados impediria a criação de uma casta de políticos autônoma, a burocracia e a corrupção" (LOUREIRO, 2006, p. 99). Os conselhos seriam o espaço que os trabalhadores teriam para discutir sobre suas próprias necessidades e aspirações, seriam o ambiente no qual os indivíduos decidiram sobre a urgência de uma pauta ou reforma, os integrantes dessas organizações estariam a par das reivindicações trabalhistas e participariam diretamente na tomada das decisões. Só nesse sentido poderíamos falar de um governo do "povo".

Os conselhos são "organizações de autodeterminação e autogoverno (ou, melhor, de preparação para o autogoverno) nas assembleias populares locais" (MARCUSE, 1973, p. 50). Assim, essas associações podem servir para reativar o espaço privado existente em cada um dos indivíduos, nos conselhos, os sujeitos podem voltar a fazer uso do pensamento e comportamento negativo que recusa as relações sociais vigentes. Podem incentivar um modo de pensar e se comportar que não se contenta com o mero negar da realidade vigente, mas imagina uma nova maneira de viver, um novo modo de vida no qual as necessidades básicas de manutenção da existência de todas as pessoas possam ser satisfeitas; uma sociedade em que os homens e mulheres dominados possam ser dispensados do trabalho penoso e usar o tempo livre para desenvolver todas as suas potencialidades.

\subsection{Os estratos desprivilegiados da sociedade unidimensional}

Os confortos que estão integrando as classes trabalhadoras às sociedades industriais avançadas ainda não alcançaram totalmente a população dos guetos, periferias, favelas. A maioria dos seus membros não participa do bem-estar proporcionado pela sociedade unidimensional, a maior parte deles nem sequer tem satisfeitas as necessidades básicas da vida. Nas periferias dos países subdesenvolvidos - ou em desenvolvimento - parte da população não tem casa própria, as ruas não tem saneamento básico, uma grande quantidade das pessoas exercem atividades informais, ou seja, empregos sem carteira assinada e, consequentemente, sem nenhum direito trabalhista estabelecido por lei: salário mínimo, carga horária de trabalho fixa, férias, décimo terceiro, etc.

Esses fatores são exemplos que podem indicar a miséria na qual estão submetidos os moradores das favelas e, ao mesmo tempo, uma demonstração de que a população das periferias são - inconsciente ou conscientemente - a "negação viva" da sociedade de consumo e do seu modo de dominação: o fornecimento de um padrão de vida elevado. Marcuse afirma que "a necessidade vital de transformação vem da própria existência da população dos guetos e das áreas 'desfavorecidas' (...)” 
(MARCUSE, 1977, p. 80). Os moradores das periferias são a contradição existente da sociedade afluente porque suas vidas são a prova empírica do quão contraditório é o próprio status quo, este, ao mesmo tempo que produz uma quantidade exagerada de produtos supérfluos permite que uma quantidade cada vez mais crescente da população viva sob a pobreza extrema.

Dessa maneira, Marcuse denuncia o quão brutal, agressiva e violenta é a sociedade predominante, pois tal civilização não está preocupada em promover uma vida racional, livre e feliz para todas as pessoas, sua preocupação fundamental é garantir lucro e posição privilegiada à classe dominante. Para atingir esse objetivo (lucro e privilégio) a sociedade de consumo precisa impor mais-repressão e manter a miséria, nisto reside a justificação da necessidade de uma revolução socialista: por que precisamos de uma revolução socialista? Porque precisamos eliminar a miséria que destrói a vida dos seres humanos; acabar com a labuta que deforma a existência dos homens e mulheres trabalhadores; destruir a sociedade em que a classe opressora se apropria de toda a riqueza produzida pela classe oprimida.

\subsection{A intelligentsia opositora}

De acordo com Marx e Engels, no Manifesto Comunista, os estratos, as camadas médias "Não são, pois, revolucionárias, mas conservadoras; mais ainda, são reacionárias, pois pretendem fazer girar para trás a roda da História” (MARX; ENGELS, 2010, p. 49). Tal afirmação parece não ser mais totalmente válida no que diz respeito às novas relações sociais prevalecentes na sociedade unidimensional. Isto porque, nas lutas contra a opressão perpetrada por essa sociedade, alguns setores da classe média (intelligentsia opositora) se põem ao lado da classe trabalhadora. Essa tomada de posição revolucionária não se dá em vista daqueles estratos compreenderem que sua existência como camadas médias está comprometida, mas porque esses setores perceberam que se o modo de vida capitalista não for detido e alterado poderá destruir a natureza e os seres humanos que o sustenta.

Para Marcuse, os técnicos, os especialistas, os engenheiros, etc., fazem parte da intelligentsia instrumentalista, mas não da intelligentsia opositora, apenas os intelectuais não conformados com o estado de coisas estabelecido fazem parte da intelligentsia opositora. Os setores da intelligentsia instrumentalista estão a serviço do establishment, seu conhecimento, especialidades e técnicas são dirigidos para perpetuar a civilização prevalecente, criar novas formas de dominação mais eficazes e aperfeiçoar as já existentes. Seu saber e suas descobertas são avaliados com base num critério, a saber: se servem ou não para gerar lucro às classes dominantes que controlam o sistema vigente. Desse modo, a sociedade predominante os obriga a servi-la, caso recusem e direcionem seu conhecimento para desenvolver descobertas e produtos que contradigam a lógica do capital, correriam o risco de perder as regalias e benefícios oferecidos pelo sistema capitalista. 
A intelligentsia instrumentalista assume um papel cada vez mais importante na manutenção da sociedade unidimensional, na medida em que orienta seu saber para aprimorar o modo e o processo de produção da sociedade capitalista. O engenheiro inventa novas máquinas, os técnicos se encarregam da sua aplicação, os especialistas desenvolvem sistemas que aperfeiçoam os meios de comunicação. Isso indica quanto àqueles intelectuais estão sob o controle do processo de produção e, dessa maneira, poderiam subverter as relações de produção estabelecidas. No entanto, afirma Marcuse,

(...) não são mais que herdeiros muito potenciais e muito teóricos, posto que ao mesmo tempo são os beneficiários bem remunerados e satisfeitos do sistema; a modificação de sua mentalidade constituiria um milagre de discernimento e lucidez (MARCUSE, 1993, p. 11, tradução nossa).

Por outro lado, há a contestação da intelligentsia opositora que "é dirigida contra a totalidade da sociedade bem-funcionante e próspera (...)" (MARCUSE, 1977, p. 73), o luxo imposto por essa civilização não conseguiu absorver a consciência dos estudantes contestadores. Esses intelectuais resistem ao modelo de vida orientado pelo consumo exacerbado de produtos supérfluos, saem às ruas em passeatas e manifestações contra a repressão, negam o pensamento e comportamento prevalecentes e repudiam a publicidade manipuladora, mentirosa e criadora de falsas necessidades ${ }^{11}$.

A intelligentsia não conformista expressa a negação do estilo de vida estabelecido quando recusa consumir as roupas e os aparelhos autodestrutivos da moda; sua contestação se torna perigosa no momento em que ocupam as ruas para denunciar a desumanidade das guerras neocoloniais; a sua oposição transforma-se em "arma da crítica" quando recusa obedecer às regras de conduta "adequadas" para o bom funcionamento do sistema. Esse modo de pensar e agir traz consigo a possibilidade de alteração da realidade presente e da construção de uma nova comunidade socialista na qual os seres humanos sejam verdadeiramente livres.

A contestação da juventude estudantil rasga o véu que cobre a opressão e descobre as formas de dominação utilizadas pelo status quo para reprimir as pessoas, antecipa a construção de um novo princípio de realidade contrário à guerra e a favor da paz, oposto ao encurtamento do caminho para a morte e em prol do alongamento da vida feliz. Para Marcuse, "a juventude está na primeira linha dos que vivem e lutam por Eros contra a Morte (...)" (MARCUSE, 2015, p. 21). Nesse sentido, a oposição da

\footnotetext{
${ }^{11}$ No seu livro $O$ homem unidimensional, Marcuse afirma que "Nós podemos distinguir entre necessidades verdadeiras e falsas. 'Falsas' são aquelas que são superimpostas ao indivíduo por interesses sociais particulares para reprimi-lo: as necessidades que perpetuam a labuta, a agressividade, a miséria e a injustiça. (...) A maior parte das necessidades predominantes de descansar, divertir-se, de comportar-se e consumir de acordo com os anúncios, de amar e odiar o que os outros amam e odeiam, pertence a categoria de falsas necessidades." (MARCUSE, 2015, p. 44).
} 
juventude à sociedade predominante é também biológica, pois lutam pela sobrevivência de seus corpos.

A melhoria das condições de trabalho, da educação, da saúde, do transporte público - redução da tarifa, passe livre estudantil, etc. - e a construção de moradia acessível e habitável são algumas das pautas proclamadas pelas manifestações de rua encabeçadas pelo movimento estudantil. Tais pautas são de caráter exclusivamente reformista, mas não se pode negar que essas conquistas poderiam amenizar a miséria a que está submetida vastas populações do globo, o próprio Marcuse "fez questão de esclarecer que não tinha nada contra reformas úteis e viáveis, capazes de atenuar os sofrimentos dos homens" (KONDER, 1998, p. 25).

Aliviar a luta pela existência significa, nesse contexto, fortalecer a resistência das classes oprimidas à repressão instituída pela classe opressora, significa elaborar as tendências revolucionárias e preparar o terreno para a revolução. As reformas podem incitar a construção de liberdades antagônicas às liberdades dadas, entrando, assim, em conflito com os interesses capitalistas. Em consequência, a exigência por verdadeira liberdade tem de ser contida se ameaça por em xeque a falsidade das relações sociais do sistema capitalista.

De acordo com a lógica de manutenção da realidade vigente, as pessoas que lutam por àquela exigência tem de ser eliminadas, e é nesse momento que as classes oprimidas têm a oportunidade de perceber e compreender os limites da sociedade prevalecente, as balas das armas utilizadas pelas forças de defesa do establishment explodem em seus ouvidos: "vós não podeis construir a comunidade socialista!" Com isso, as forças de oposição aprendem que para viver uma vida verdadeiramente racional, livre e feliz não é suficiente lutar por reformas, mas lutar pela destruição da sociedade capitalista.

No entanto, os estudantes ainda são uma força política desorganizada no que se refere às questões internas: divergência quanto às ideias políticas que dirigem o movimento (socialista, anarquista, etc.), a discordância em relação a esses problemas pode gerar divisões dentro do movimento e prejudicar a luta por objetivos comuns essenciais. Além disso, o movimento permanece isolado, tem dificuldades de estabelecer o diálogo político revolucionário com os trabalhadores e, na maioria das vezes, não consegue se quer ganhar o seu apoio. Esses fatores são algumas consequências da falta de organização da intelligentsia opositora, porém esse estado de coisas não impede que Marcuse continue a acreditar que a contestação dos intelectuais pode dá início à recusa em massa da sociedade capitalista.

Revolucionário na teoria, nos instintos e nos objetivos finais, o movimento estudantil não é uma força revolucionária, talvez nem mesmo uma vanguarda, visto não haver massas capazes e desejosas de o seguir, mas é o fermento das metrópoles capitalistas dominadoras e inflexíveis: dá testemunho da verdade da alternativa - 
a verdadeira necessidade e a verdadeira possibilidade de uma sociedade livre (MARCUSE, 1977, p. 84-85).

\section{Conclusão}

A sociedade unidimensional - por meio dos confortos oferecidos pela tecnologia - está conseguindo integrar, cada vez mais, a classe trabalhadora ao modo de vida vigente. Para Marcuse, esse estado de coisas não é imutável, pelo contrário, ele pode ser alterado. A única força capaz de efetivar essa mudança é a classe trabalhadora, entretanto, ela está integrada demais para perceber e compreender a necessidade de uma transformação da realidade existente. Para fazer frente a essa aparente ausência de esperança de uma vida melhor, Marcuse mostra que há tendências na civilização estabelecida capazes de reativar a atitude radical dos trabalhadores, essas tendências o filósofo alemão denomina de "catalisadores".

O conceito "catalisador" significa as tendências quantitativamente menores de desintegração existentes no status quo, que podem romper a consciência integrada da classe trabalhadora e reativar seu pensamento e práxis revolucionária. Segundo Marcuse, nas décadas de 1960 e 70, existiam pelo menos cinco catalisadores que, através de suas lutas poderiam dar início ao processo de destruição da dominação e efetivação da libertação da classe oprimida. Essas tendências são: 1) os movimentos de libertação nos países subdesenvolvidos; 2) as novas estratégias dos trabalhadores na Europa; 3) os estratos desprivilegiados da sociedade unidimensional; 4) os intelectuais de oposição e 5) os movimentos de contestação nos países soviéticos.

A luta do primeiro catalisador é uma ameaça para o establishment porque denuncia a brutalidade imposta pelas sociedades industriais avançadas aos países subdesenvolvidos e, ao mesmo tempo, apresenta a estratégia da luta armada como meio de resistência e combate utilizado pelos rebeldes para enfrentar a repressão. $\mathrm{O}$ segundo catalisador pode quebrar a sólida estrutura do sistema capitalista porque desenvolve como método de luta a reconstrução dos "sovietes", dos "conselhos", que são, de modo geral, o espaço para a criação da autonomia revolucionária da classe dominada.

O terceiro catalisador pode reativar a consciência e ação revolucionária da classe trabalhadora porque é a negação viva da realidade dada. Os desprivilegiados dessa civilização vivem na miséria, lhes falta comida, roupa e moradia, eles são, simultaneamente, a justificativa e a demonstração da necessidade de uma revolução socialista. O quarto catalisador pode romper a consciência integrada dos trabalhadores porque tenta - através da recusa do modelo de vida imposto, através das manifestações de rua - tornar perceptíveis e compreensíveis as contradições e as formas de dominação da realidade vigente. Portanto, os catalisadores, através das suas formas de resistência e luta, tentam mostrar a irracionalidade do modo de vida existente, tentam fazer ressurgir a consciência e ação radical capaz de destruir a 
sociedade unidimensional.

\section{Referências}

AQUINO, J. K. S. O conceito de cálculo histórico em Herbert Marcuse. In: ANAIS DA III SEMANA DE ECONOMIA POLÍTICA - Acumulação de Capital e Emancipação Humana: Subdesenvolvimento, Crise Ambiental e lutas Sociais no Século XXI. 3., 2016, Fortaleza. Anais. Fortaleza, 2016, p. 10.

CARNEIRO, S. R. G. Resenha. Collected papers of Herbert Marcuse, (Marxism, revolution, and utopia) Cadernos de Ética e Filosofia Política. São Paulo: n. 25, p. 212225, 2014.

IVO, R. S. L. Considerações preliminares sobre o significado do conceito "nãoliberdade" no primeiro capítulo de $O$ homem unidimensional de Herbert Marcuse. In: ANAIS DA III SEMANA DE ECONOMIA POLÍTICA - Acumulação de Capital e Emancipação Humana: Subdesenvolvimento, Crise Ambiental e lutas Sociais no Século XXI. 3., 2016, Fortaleza. Anais. Fortaleza, 2016, p. 10.

KONDER, L. Marcuse, Revolucionário. PHYSIS: Rev. Saúde Coletiva. Rio de Janeiro, v. 8, n. 1, pp. 15-28, 1998.

LOUREIRO, I. M. F. R. Os conselhos na revolução alemã de 1918/19. Crítica Marxista. São Paulo, n. 23, pp. 97-111, 2006. Disponível em:

http://www.ifch.unicamp.br/criticamarxista/arquivos_biblioteca/artigo13oartigoa.pd f Acesso em: 13 nov. 2016.

MARCUSE, Herbert. Eros e civilização: uma interpretação filosófica do pensamento de Freud. Tradução de Álvaro Cabral. 8. ed. [Reimpr]. Rio de Janeiro: LTC, 2015a.

. O homem unidimensional: estudos da ideologia da sociedade industrial avançada. Tradução de Robespierre de Oliveira, Deborah Christina Antunes e Rafael Cordeiro Silva. São Paulo: Edipro, 2015b.

Prefacio a la edición francesa. In: MARCUSE, Herbert. El hombre unidimensional: ensayo sobre la ideología de la sociedad industrial avanzada. Traducción del Antonio Elorza. Barcelona: Planeta-De Agostini, 1993.

. Um ensaio sobre a libertação. Tradução de Maria Ondina Braga. Lisboa: Livraria Bertrand, 1977.

. Contra-revolução e revolta. Tradução de Álvaro Cabral. Rio de Janeiro:

Zahar Editores, 1973.

. A obsolescência do marxismo. In: MARCUSE, Herbert; ADORNO,

Theodor; HABERMAS, Jügern. As opções da esquerda. Tradução de. ed. Rio de Janeiro: Paz e Terra, 1972, p. 193-203.

MARX, Karl. Crítica da filosofia do direito de Hegel - Introdução. In:

Crítica da filosofia do direito de Hegel, 1843. Tradução de Rubens Enderle e Leonardo de Deus. 3. ed. São Paulo: Boitempo, 2013.

MARX, Karl; ENGELS, Friedrich. Manifesto Comunista. Tradução de Álvaro Pina e Ivana Jinkings. 1. ed. rev. São Paulo: Boitempo, 2010. 
MARX, Karl. Ad Feuerbach. In: ; ENGELS, Friedrich. A ideologia alemã: crítica da mais recente filosofia alemã em seus representantes Feurbach, B. Bauer e Stirner, e do socialismo alemão em seus diferentes profetas (1845-1846). Tradução de Rubens Enderle, Nélio Schneider e Luciano Cavini Martorano. 1. ed. São Paulo: Boitempo, 2007.

OLIVEIRA, Robespierre de. O papel da filosofia na teoria crítica de Herbert Marcuse. São Paulo: Editora Unesp, 2012.

PISANI, M. M. A “máquina” como instrumento de controle na sociedade tecnológica - Herbert Marcuse crítico da tecnologia. In: Congresso Internacional Indústria Cultural Hoje. 1., 2006, Piracicaba. Anais. Piracicaba, 2006, p. 14.

SILVA, R. C. Traduzir Marcuse: O homem unidimensional. Ouro Preto, n. 18, pp. 146150, 2015. Disponível em: http://www.raf.ufop.br/pdf/artefilosofia_18/146-150.pdf Acesso em: 25 jan. 2017.

Submissão: 01.05.2017 / Aceite: 30.05.2017 